\title{
MolMod - an open access database of force fields for molecular simulations of fluids
}

\author{
Simon Stephan, Martin T. Horsch, Jadran Vrabec \& Hans Hasse
}

To cite this article: Simon Stephan, Martin T. Horsch, Jadran Vrabec \& Hans Hasse (2019): MolMod - an open access database of force fields for molecular simulations of fluids, Molecular Simulation

To link to this article: https://doi.org/10.1080/08927022.2019.1601191

\section{Published online: 08 Apr 2019.}

Submit your article to this journal

View Crossmark data $\asymp$ 


\title{
MolMod - an open access database of force fields for molecular simulations of fluids
}

\author{
Simon Stephan ${ }^{a}$, Martin T. Horsch ${ }^{b}$, Jadran Vrabec ${ }^{c}$ and Hans Hasse ${ }^{a}$

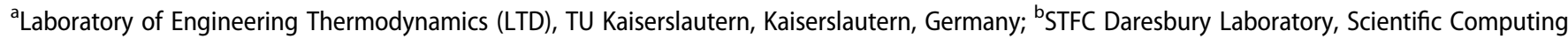 \\ Department, Warrington, UK; ${ }^{C}$ Thermodynamics and Process Engineering, TU Berlin, Berlin, Germany
}

\begin{abstract}
The MolMod database is presented, which is openly accessible at http://molmod.boltzmann-zuse.de and contains intermolecular force fields for over 150 pure fluids at present. It was developed and is maintained by the Boltzmann-Zuse Society for Computational Molecular Engineering (BZS). The set of molecular models in the MolMod database provides a coherent framework for molecular simulations of fluids. The molecular models in the MolMod database consist of Lennard-Jones interaction sites, point charges, and point dipoles and quadrupoles, which can be equivalently represented by multiple point charges. The force fields can be exported as input files for the simulation programmes ms 2 and $I s 1$ mardyn, GROMACS, and LAMMPS. To characterise the semantics associated with the numerical database content, a force field nomenclature is introduced that can also be used in other contexts in materials modelling at the atomistic and mesoscopic levels. The models of the pure substances that are included in the database were generally optimised such as to yield good representations of experimental data of the vapour-liquid equilibrium with a focus on the vapour pressure and the saturated liquid density. In many cases, the models also yield good predictions of caloric, transport, and interfacial properties of the pure fluids. For all models, references to the original works in which they were developed are provided. The models can be used straightforwardly for predictions of properties of fluid mixtures using established combination rules. Input errors are a major source of errors in simulations. The MolMod database contributes to reducing such errors.
\end{abstract}

\section{ARTICLE HISTORY}

Received 14 January 2019

Accepted 26 March 2019

\section{KEYWORDS}

Molecular models; force field database; thermophysical properties; molecular dynamics; Monte Carlo

\section{Introduction}

Reliable information on thermophysical properties is of fundamental importance for the development and optimisation of processes in chemical engineering, but also in many other fields, such as energy conversion and storage. With the increasing availability of computational resources, simulation techniques are today an attractive alternative to classical experiments in laboratories to obtain accurate thermophysical properties [1-3]. Compared to laboratory experiments, computer experiments have the advantage that problematic substances (toxic, flammable, explosive, etc.) and extreme conditions can be studied without any problems. Computer experiments, like molecular dynamics (MD) and Monte Carlo (MC), have therefore become an accepted complement and sometimes even substitute to traditional experimental work. Therefore, many scientific journals that were afore focussed on reporting experimental data on thermophysical properties have started recently to accept and also call for corresponding molecular simulation data [4]. Especially phase equilibria, transport, and interfacial properties of pure fluids and fluid mixtures are of special interest in chemical engineering and also in many other fields. Knowledge of these thermophysical properties is often required for a wide range of temperature and pressure and with a high accuracy. The accuracy of thermophysical property data obtained by molecular simulation, in the sense that the simulation shall reproduce properties of real substances, depends mainly on the applied force field. The development of suitable force fields is therefore of prime importance for the success of molecular methods in materials modelling. Moreover, it is not sufficient that good force fields are developed. They must also be made available to potential users in a way that they can be handled easily in the simulation package with which the user wants to carry out his work. This is of special importance, as input errors are known to be one of the major sources of simulation errors[5]. The present work addresses this challenge.

Generalised force fields, such as CHARMM [6-9], AMBER [10-12], or GROMOS $[13,14]$, are mainly used for biological systems, and focus therefore on aqueous systems at near-ambient conditions. Such generalised force fields mostly do not satisfy the accuracy that is required in chemical engineering for data on phase equilibrium, transport, and interfacial properties. Force fields that are particularly aiming at an accurate description of phase equilibria are for example OPLS [15-17], TraPPE [18], and OPPE [19-21]. These are transferable force fields which means that the interaction parameters of chemical groups or atoms can be transferred among substance families, like alkanes.

The molecular models of the pure substances in the MolMod database [22] were tailored to describe thermophysical properties of that substance. Only fluid properties are considered. The interaction parameters of a molecular species are only valid for that very substance, i.e. no extrapolation to other substances is intended. The advantage of this individual parametrisation lies in the high accuracy of each model which can be achieved. Furthermore, it is known that using 
such models, extrapolations to other thermophysical properties and other conditions than those that were used in the parametrisation are often successful [23-26]. The models can also be applied for studying fluid mixtures using well-established combination rules [27]. The force fields in the MolMod database were developed under the auspices of the Boltzmann-Zuse Society of Computational Molecular Engineering (BZS) as described in more than 30 original peer-reviewed publications. The molecular models were parametrised in a consistent way with respect to vapour-liquid equilibrium data, which is therefore described very well. Other pure component properties, such as homogeneous $p v T$ data, caloric properties, speed of sound, and interfacial properties, predicted from these models were found to be in good agreement with experimental data where available [25, 28-33]. The MolMod database currently consists of molecular models for approximately 150 pure substances of mainly moderately sized molecules that are modelled as rigid bodies. Also multiple models for ions are included. The molecular models in the MolMod database consist of LennardJones interaction sites, point charges, and point dipoles and quadrupoles.

The models can also be combined to describe mixtures. Usually, the Lorentz-Berthelot combination rules are found to yield acceptable predictions of the behaviour of binary and multicomponent mixtures. However, the accuracy is then often below that which is achieved for the pure substances. To obtain a similar accuracy also for mixtures, it is often sufficient to adjust a single state-independent binary parameter in the Berthelot combination rule for the dispersive cross-interaction $[27,34]$.

The core of the MolMod database is a download feature for several molecular simulation codes. The codes that are supported in the present version are LAMMPS [35], GROMACS [36], $m s 2$ [37], and $l s 1$ mardyn [38]. Databases that provide input files for molecular interactions and generalised force fields have already been introduced in the fields of microbiology and chemistry $[8,9,12,39-42]$, but to the best of our knowledge not for individually parametrised highly accurate molecular force fields, focussing on the description of thermophysical properties of fluids.

\section{MolMod database}

The MolMod database http://molmod.boltzmann-zuse.de (Web frontend cf. Figure 1) provides a range of search functionalities, e.g. for substances, CAS numbers, model classes, etc. Each molecular model has an individual page, which contains the full specification of the molecular model and the download links for the input files. Also, each molecular model is hyperlinked to the original publication. The database contains a comprehensive nomenclature section that describes the specifications in the input files for all supported simulation programmes to facilitate the simulators integrating the force fields in their simulation workflows. Known misprints in publications are clearly emphasised in the database.

All force fields in the MolMod database are currently rigid single- or multi-site models, consisting of Lennard-Jones 12-6 interaction sites, point charges, point dipoles, and point quadrupoles. All supported interaction potentials are pairwise additive.
In all models, the repulsion and dispersion between two particles $i$ and $j$ at a distance $r_{i j}$ are described by the standard Lennard-Jones $12-6$ potential

$$
u_{i j}^{\mathrm{LJ}}(r)=4 \varepsilon\left[\left(\frac{\sigma}{r_{i j}}\right)^{12}-\left(\frac{\sigma}{r_{i j}}\right)^{6}\right],
$$

where $\varepsilon$ is the dispersion energy and $\sigma$ the size parameter of an interaction site. The interaction between two different LennardJones sites is described by the Lorentz-Berthelot combination rules $[43,44]$.

The electrostatic interactions are modelled by point charges, point dipoles, and point quadrupoles. The latter two describe the electrostatic field of two and four point charges of the same magnitude, respectively. The advantage of higher order polarities in molecular simulations lies in a reduction of computational effort of up to $60 \%$ compared to a corresponding arrangement of point charges [45]. It has also been claimed that multipoles give a better description of electrostatic interactions [46].

The electrostatic potential between two point charges $q_{i}$ and $q_{j}$ is given by Coulomb's law

$$
u_{i j}^{\mathrm{ee}}\left(r_{i j}\right)=\frac{1}{4 \pi \epsilon_{0}} \frac{q_{i} q_{j}}{r_{i j}},
$$

where $q_{i}$ is the magnitude of the charge $i$ and $r_{i j}$ the distance between two point charges $i$ and $j$.

A point dipole describes the electrostatic field of two point charges with equal magnitude, but opposite sign at a mutual distance $a \rightarrow 0$. Its dipole moment magnitude is defined by $\mu=q a$. The electrostatic potential between two point dipoles with the moments $\mu_{i}$ and $\mu_{j}$ at a distance $r_{i j}$ is given by [47-49]

$$
\begin{aligned}
& u_{i j}^{\mathrm{dd}}\left(r_{i j}, \theta_{i}, \theta_{j}, \phi_{i j}\right) \\
& \quad=\frac{1}{4 \pi \epsilon_{0}} \frac{\mu_{i} \mu_{j}}{r_{i j}^{3}}\left[\left(\sin \left(\theta_{i}\right) \sin \left(\theta_{j}\right) \cos \left(\phi_{i j}\right)-2 \cos \left(\theta_{i}\right) \cos \left(\theta_{j}\right)\right],\right.
\end{aligned}
$$

where the angles $\theta_{i}, \theta_{j}$ and $\phi_{i j}$ indicate the relative angular orientation of the two point dipoles with the former indicating the angle between the dipole direction and the distance vector of the two interacting dipoles and $\phi_{i j}$ being the azimuthal angle of the two dipole directions.

A linear point quadrupole describes the electrostatic field induced either by two collinear point dipoles with the same moment, but opposite orientation at a distance $a \rightarrow 0$ or three point charges, e.g. $(q,-2 q, q)$. The quadrupole magnitude $Q$ is defined as $Q=2 q d^{2}$, where $q$ is the characteristic magnitude of the three charges, and $d$ is the distance between each of the outer charges (magnitude $q$ ) and the $-2 q$ charges in the centre. The interaction potential is given by [47-49]

$$
\begin{aligned}
u_{i j}^{\mathrm{qq}}\left(r_{i j}, \theta_{i}, \theta_{j}, \phi_{i j}\right) \\
=\frac{1}{4 \pi \epsilon_{0}} \frac{3}{4} \frac{Q_{i} Q_{j}}{r_{i j}^{5}}\left[1-5\left(\left(\cos \theta_{i}\right)^{2}+\left(\cos \theta_{i}\right)^{2}\right)\right. \\
\quad-15\left(\cos \theta_{i}\right)^{2}\left(\cos \theta_{j}\right)^{2} \\
\left.\quad+2\left(\sin \theta_{i} \sin \theta_{j} \cos \phi_{i j}-4 \cos \theta_{i} \cos \theta_{j}\right)^{2}\right],
\end{aligned}
$$




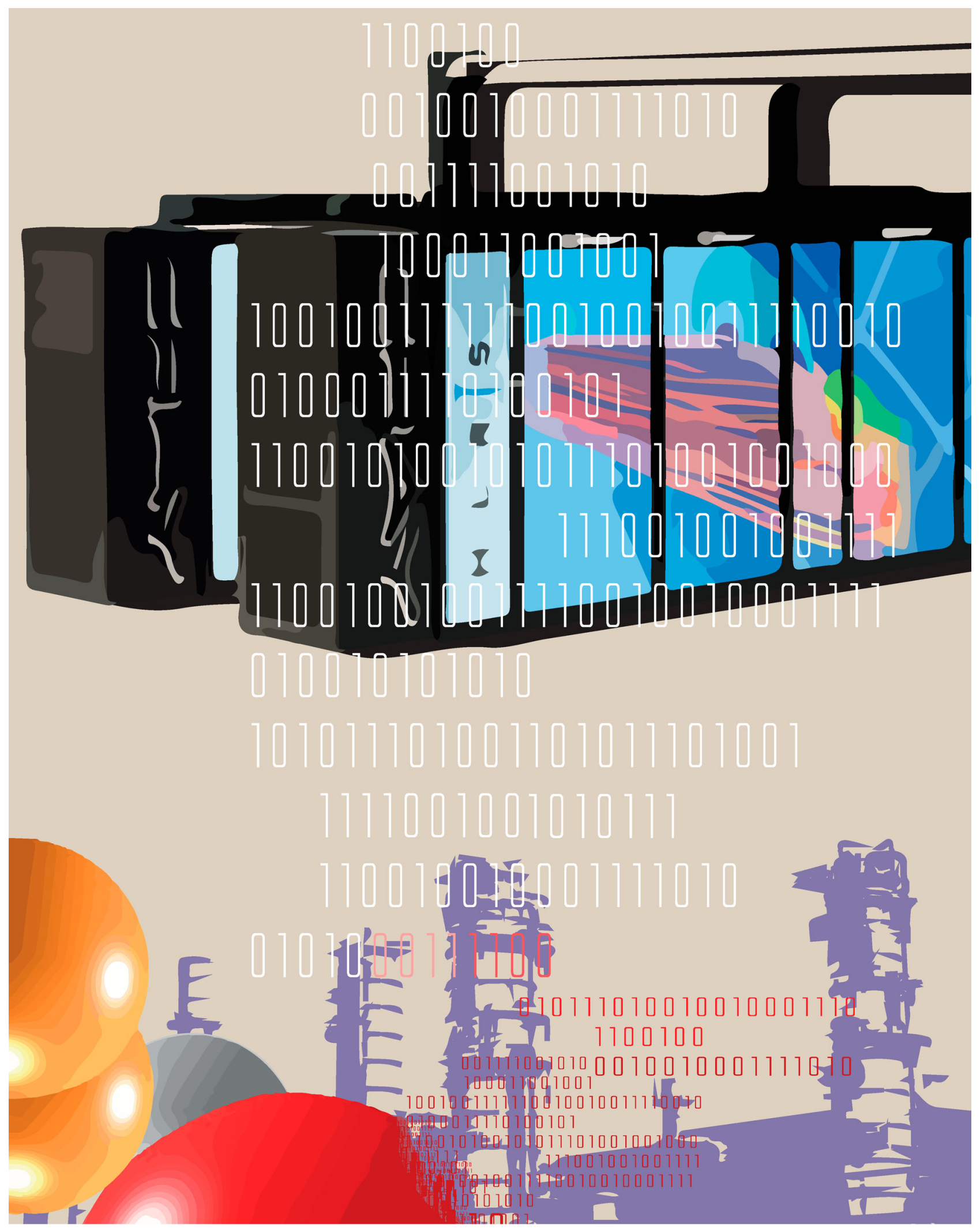

Figure 1. (Colour online) Graphical design of the MolMod homepage: http://molmod.boltzmann-zuse.de (colour online).

where the angles $\theta_{i}, \theta_{j}$, and $\phi_{i j}$ indicate the relative angular orientation of the two point quadrupoles. The interaction potentials between unlike electrostatic site types can also be derived from the laws of electrostatics straightforwardly.
For a detailed derivation of these equations, cf. Gray and Gubbins [48].

For mixtures of fluids from the MolMod database, the modified Lorentz-Berthelot combination rules proved to give 
an accurate description of fluid mixtures [27, 34, 50]

$$
\begin{gathered}
\sigma_{i j}=\eta \frac{\sigma_{i}+\sigma_{j}}{2}, \\
\varepsilon_{i j}=\xi \sqrt{\varepsilon_{i} \varepsilon_{j}},
\end{gathered}
$$

where $\xi$ and $\eta$ are state-independent adjustable binary interaction parameters to explicitly consider the non-ideality of the respective mixture. Binary interaction parameters $\xi$ adjusted to binary vapour-liquid equilibrium data $[34,51]$ are available for approximately 400 mixtures of molecular models from the MolMod database. It could be shown that the original Lorentz combination rule, i.e. $\eta=1$, is a good approximation in most cases [27]. Using the input files provided by the MolMod database for the simulation of mixtures with the programmes $m s 2$ and $l s 1$, mardyn is straightforward $[37,38]$ as their syntax only requires the additional specification of the mole fractions and eventually the binary interaction parameters for mixtures. However, the numeric values for the binary parameters $\xi$ are currently not provided by the database.

The parametrisation of molecular models that are part of the MolMod database was usually carried out in two steps: The geometry and charge distribution of multi-site models was obtained from quantum chemical calculations. The remaining intermolecular interactions were then optimised to vapourliquid equilibrium data, i.e. saturated liquid density, vapour pressure, and enthalpy of vaporisation. Also, automated simulation and optimisation workflows have been employed, operating in the parameter space locally $[52,53]$ as well as globally [54], which leads to a significant reduction of the effort. Multicriteria optimisation based on the analysis of a Pareto set has also been employed for the parametrisation lately [55-57] to explicitly consider conflicting objectives. The agreement with experimental data is typically found to be within $4 \%$ for the vapour pressure, $0.5 \%$ for the saturated liquid density, and $3 \%$ for the enthalpy of vaporisation. Predicted thermophysical properties that were not considered during the parametrisation agree with experimental data approximately within $10 \%$ for transport properties, and $20 \%$ for surface tension data. In some cases, the deviations of the model behaviour from the available experimental data are smaller than the experimental uncertainty for a wide variety of thermophysical properties [26]. Some of the molecular models have also been employed to complement experimental data sets for the development of high-accuracy equations of state $[30,58]$ for engineering applications.

Table 1 summarises the molecular substances that are currently available in the MolMod database, sorted by the number of carbon atoms. The database contains molecular models of different substance classes, e.g. organic substances, noble gases, and chlorofluorocarbons. Organic substances in the database are from different chemical families, like alkanes, alkenes, alcohols, aromatics, amines, ketones, nitriles, acids, etc. Molecular models for numerous substances of fundamental importance for the chemical industry are covered, such as methanol, ethanol, formic acid, ammonia, formaldehyde, hydrogen cyanide, acetonitrile, ethylene oxide, toluene, ethylene glycol, acetone, etc. A second focus of the MolMod database comprises important refrigerants, of which it contains approximately 30 , such as R134a, R22, R12, R227ea. The MolMod database also contains molecular models for substances that are gases at ambient conditions and are for example important in environmental science, such as $\mathrm{O}_{2}, \mathrm{~N}_{2}, \mathrm{CO}, \mathrm{CO}_{2}, \mathrm{~N}_{2} \mathrm{O}, \mathrm{H}_{2}, \mathrm{H}_{2} \mathrm{O}, \mathrm{SO}_{2}$, or Ar. Also some models for ions are available in the MolMod database [77-79].

\section{Available input formats}

Questions regarding the molecular topology and the interaction specifications in a certain simulation programme are among the most common ones in the mailing lists, for example for LAMMPS [35] and GROMACS [36]. The 'by hand' implementation of force fields is a sensitive task [5] due to questions like angle definitions, units, and geometry specifications, etc. Ready-to-use and validated force field input files are - where available - a welcome support to simulators. The MolMod database currently provides input files for the simulation programmes LAMMPS [35], GROMACS [36], ms2 [37], and $l s 1$ mardyn [38]. Since these molecular simulation codes are based on different approaches to realise for example multipole interactions, the geometry definition or the rigidity constraint of molecules, on the fly conversion routines were implemented in the database.

Since most simulation programmes cannot handle point dipoles or point quadrupoles explicitly, they are converted on the fly into the corresponding configuration of point charges, i.e $(+q,-q)$ for dipoles and $(+q,-2 q,+q)$ for quadrupoles. Despite the fact that point multipoles are computationally much cheaper than a corresponding configuration of point charges, both are physically equivalent [80]. As there is one degree of freedom for replacing point dipoles and point quadrupoles by point charges, a rational choice for one parameter either the elongation or the magnitude of the point charge - has to be made. This problem was addressed in the work of Engin et al. [80] for the molecular model class of 2CLJD and 2CLJQ. Engin et al. [80] could show that setting the distance $a$ or $d$ between the two point charges to $\sigma / 20$, where $\sigma$ is the size parameter of the Lennard-Jones site, leads to excellent agreement between a multipole and the corresponding configuration of point charges. The magnitude of the two point charges $q$ is then straightforwardly computed as

$$
q=\frac{\mu}{a}=\frac{20 \mu}{\sigma},
$$

for dipoles and

$$
q=\frac{Q}{2 d^{2}}=\frac{200 Q}{\sigma^{2}},
$$

for quadrupoles. This method was extended in the MolMod database to arbitrary molecular structures by calculating the parameter $a$ or $d$ by means of the Lennard-Jones interaction site closest to the point dipole according to the Euclidean norm. Also, the geometry of the molecular models is adapted to the demands of each simulation programme, as some require internal Z-matrix coordinates and others $x y z$-coordinates. Particular care was also taken regarding the units of each numeric value. 
Table 1. List of molecular force fields currently available in the molMod database.

\begin{tabular}{|c|c|c|c|}
\hline Substance & CAS No. & Name & Reference \\
\hline $\operatorname{Ar}$ & $7440-37-1$ & Argon & {$[59,60]$} \\
\hline $\mathrm{Br}_{2}$ & $7726-95-6$ & Bromine & {$[56,59]$} \\
\hline $\mathrm{Cl}_{2}$ & $7782-50-5$ & Chlorine & [59] \\
\hline $\mathrm{F}_{2}$ & $7782-41-4$ & Fluorine & {$[56,59]$} \\
\hline $\mathrm{H}_{2}$ & $1333-74-0$ & Hydrogen & [61] \\
\hline $\mathrm{H}_{2} \mathrm{O}$ & $7732-18-5$ & Water & {$[62]$} \\
\hline $\mathrm{H}_{4} \mathrm{~N}_{2}$ & $302-01-2$ & Hydrazine & [63] \\
\hline $\mathrm{HCl}$ & 7647-01-0 & Hydrochloric acid & [23] \\
\hline $\mathrm{I}_{2}$ & $7553-56-2$ & lodine & [59] \\
\hline $\mathrm{Kr}$ & $7439-90-9$ & Krypton & {$[59,60]$} \\
\hline $\mathrm{N}_{2}$ & $7727-37-9$ & Nitrogen & {$[56,59]$} \\
\hline $\mathrm{N}_{2} \mathrm{O}$ & $10024-97-2$ & Nitrous oxide & [57] \\
\hline $\mathrm{Ne}$ & 7440-01-9 & Neon & [59] \\
\hline $\mathrm{NH}_{3}$ & 7664-41-7 & Ammonia & {$[28]$} \\
\hline $\mathrm{O}_{2}$ & $7782-44-7$ & Oxygen & {$[56,59]$} \\
\hline $\mathrm{SF}_{6}$ & $2551-62-4$ & Sulphur hexafluoride & [59] \\
\hline $\mathrm{SO}_{2}$ & $7446-09-5$ & Sulphur dioxide & [64] \\
\hline $\mathrm{Xe}$ & $7440-63-3$ & Xenon & {$[59,60]$} \\
\hline $\mathrm{CBr}_{2} \mathrm{~F}_{2}$ & $75-61-6$ & Dibromodifluoromethane & [65] \\
\hline $\mathrm{CBrCl}_{3}$ & $75-62-7$ & Bromotrichloromethane & [65] \\
\hline $\mathrm{CBrClF}_{2}$ & $353-59-3$ & Bromochlorodifluoromethane & [65] \\
\hline $\mathrm{CBrF}_{3}(\mathrm{R} 13 \mathrm{~B} 1)$ & $75-63-8$ & Bromotrifluoromethane & [65] \\
\hline $\mathrm{CCl}_{2} \mathrm{O}$ & $75-44-5$ & Phosgene & [23] \\
\hline $\mathrm{CCl}_{4}$ & $56-23-5$ & Carbon tetrachloride & {$[29,59]$} \\
\hline CCIN & $506-77-4$ & Cyanogen chloride & [66] \\
\hline $\mathrm{CF}_{2} \mathrm{Cl}_{2}(\mathrm{R} 12)$ & $75-71-8$ & Dichlorodifluoromethane & [65] \\
\hline $\mathrm{CF}_{3} \mathrm{Cl}(\mathrm{R} 13)$ & $75-72-9$ & Chlorotrifluoromethane & [65] \\
\hline $\mathrm{CF}_{4}$ & $75-73-0$ & Tetrafluoromethane & [59] \\
\hline $\mathrm{CFCl}_{3}(\mathrm{R} 11)$ & $75-69-4$ & Trichloromonofluoromethane & [65] \\
\hline $\mathrm{CH}_{2} \mathrm{Br}_{2}$ & 74-95-3 & Dibromomethane & [65] \\
\hline $\mathrm{CH}_{2} \mathrm{BrCl}$ & 74-97-5 & Bromochloromethane & [65] \\
\hline $\mathrm{CH}_{2} \mathrm{Cl}_{2}$ & $75-09-2$ & Methylene chloride & [65] \\
\hline $\mathrm{CH}_{2} \mathrm{~F}_{2}(\mathrm{R} 32)$ & $75-10-5$ & Difluoromethane & [65] \\
\hline $\mathrm{CH}_{2} \mathrm{I}_{2}$ & $75-11-6$ & Methylene iodide & [65] \\
\hline $\mathrm{CH}_{2} \mathrm{O}$ & $50-00-0$ & Formaldehyde & [64] \\
\hline $\mathrm{CH}_{2} \mathrm{O}_{2}$ & $64-18-6$ & Formic acid & [67] \\
\hline $\mathrm{CH}_{3} \mathrm{Br}$ & 74-83-9 & Methyl bromide & [65] \\
\hline $\mathrm{CH}_{3} \mathrm{Cl}$ & 74-87-3 & Methyl chloride & [65] \\
\hline $\mathrm{CH}_{3} \mathrm{~F}(\mathrm{R} 41)$ & $593-53-3$ & Methyl fluoride & [65] \\
\hline $\mathrm{CH}_{3} \mathrm{I}$ & $74-88-4$ & Methyl iodide & [65] \\
\hline $\mathrm{CH}_{3} \mathrm{NO}_{2}$ & $75-52-5$ & Nitromethane & [64] \\
\hline $\mathrm{CH}_{4}$ & $74-82-8$ & Methane & {$[59,60]$} \\
\hline $\mathrm{CH}_{4} \mathrm{O}$ & 67-56-1 & Methanol & [25] \\
\hline $\mathrm{CH}_{5} \mathrm{~N}$ & 74-89-5 & Methylamine & [68] \\
\hline $\mathrm{CH}_{6} \mathrm{~N}_{2}$ & $60-34-4$ & Monomethylhydrazine & [63] \\
\hline $\mathrm{CHBr}_{3}$ & $75-25-2$ & Bromoform & [65] \\
\hline $\mathrm{CHCl}_{2} \mathrm{~F}$ & $75-43-4$ & Dichlorofluoromethane & [65] \\
\hline $\mathrm{CHCl}_{3}$ & $67-66-3$ & Chloroform & [65] \\
\hline $\mathrm{CHF}_{2} \mathrm{Cl}(\mathrm{R} 22)$ & $75-45-6$ & Difluorochloromethane & [65] \\
\hline $\mathrm{CHF}_{3}(\mathrm{R} 23)$ & $75-46-7$ & Fluoroform & [65] \\
\hline CHN & 74-90-8 & Hydrogen cyanide & [64] \\
\hline $\mathrm{CO}$ & $630-08-0$ & Carbon monoxide & [65] \\
\hline $\mathrm{CO}_{2}$ & $124-38-9$ & Carbon dioxide & {$[24,59]$} \\
\hline $\mathrm{CS}_{2}$ & $75-15-0$ & Carbon disulphide & [59] \\
\hline $\mathrm{C}_{2} \mathrm{Br}_{2} \mathrm{~F}_{4}$ & $124-73-2$ & 1,2-Dibromotetrafluoroethane & [65] \\
\hline $\mathrm{C}_{2} \mathrm{BrF}_{3}$ & $598-73-2$ & Bromotrifluoroethylene & [65] \\
\hline $\mathrm{C}_{2} \mathrm{Cl}_{2} \mathrm{~F}_{4}(\mathrm{R} 114)$ & $76-14-2$ & $\begin{array}{l}\text { 1,2-Dichloro-1,1,2,2- } \\
\text { tetrafluoroethane }\end{array}$ & [65] \\
\hline $\mathrm{C}_{2} \mathrm{Cl}_{3} \mathrm{~F}_{3}(\mathrm{R} 113)$ & $76-13-1$ & $\begin{array}{l}\text { 1,1,2-Trichloro-1,2,2- } \\
\text { trifluoroethane }\end{array}$ & [65] \\
\hline $\mathrm{C}_{2} \mathrm{Cl}_{4}$ & $127-18-4$ & Tetrachloroethylene & {$[56,59]$} \\
\hline $\mathrm{C}_{2} \mathrm{Cl}_{4} \mathrm{~F}_{2}$ (R112a) & $76-11-9$ & $\begin{array}{l}\text { 1,1,1,2-Tetrachloro-2,2- } \\
\text { difluoroethane }\end{array}$ & [65] \\
\hline $\mathrm{C}_{2} \mathrm{ClF}_{3}$ & $79-38-9$ & Chlorotrifluoroethene & [65] \\
\hline $\mathrm{C}_{2} \mathrm{ClF}_{5}(\mathrm{R} 115)$ & $76-15-3$ & Pentafluoroethyl chloride & [65] \\
\hline $\mathrm{C}_{2} \mathrm{~F}_{4}$ & $116-14-3$ & Tetrafluoroethylene & {$[56,59]$} \\
\hline $\mathrm{C}_{2} \mathrm{~F}_{6}$ & $76-16-4$ & Perfluoroethane & [59] \\
\hline $\mathrm{C}_{2} \mathrm{H}_{2}$ & $74-86-2$ & Acetylene & {$[56,59]$} \\
\hline $\mathrm{C}_{2} \mathrm{H}_{2} \mathrm{Cl}_{3} \mathrm{~F}$ & $27154-33-2$ & 1,1,1-Trichloro-2-fluoroethane & [65] \\
\hline $\mathrm{C}_{2} \mathrm{H}_{2} \mathrm{Cl}_{4}$ & $630-20-6$ & $1,1,1,2-$ Tetrachloroethane & [65] \\
\hline $\mathrm{C}_{2} \mathrm{H}_{2} \mathrm{~F}_{2}$ & $75-38-7$ & 1,1-Difluoroethene & [65] \\
\hline $\mathrm{C}_{2} \mathrm{H}_{2} \mathrm{~F}_{4}$ (R134) & $359-35-3$ & 1,1,2,2-Tetrafluoroethane & [65] \\
\hline $\mathrm{C}_{2} \mathrm{H}_{2} \mathrm{~F}_{4}$ (R134a) & $811-97-2$ & Norflurane & [65] \\
\hline $\mathrm{C}_{2} \mathrm{H}_{3} \mathrm{Cl}$ & $75-01-4$ & Vinyl chloride & [65] \\
\hline
\end{tabular}

(Continued)
Table 1. Continued.

\begin{tabular}{|c|c|c|c|}
\hline Substance & CAS No. & Name & Reference \\
\hline $\begin{array}{r}\mathrm{C}_{2} \mathrm{H}_{3} \mathrm{Cl}_{2} \mathrm{~F} \\
(\mathrm{R} 141 \mathrm{~b})\end{array}$ & $1717-00-6$ & 1,1-Dichloro-1-fluoroethane & [65] \\
\hline $\mathrm{C}_{2} \mathrm{H}_{3} \mathrm{Cl}_{3}$ & $71-55-6$ & Methylchloroform & [65] \\
\hline $\mathrm{C}_{2} \mathrm{H}_{3} \mathrm{Cl}_{3}$ & $79-00-5$ & 1,1,2-Trichloroethane & [65] \\
\hline $\begin{array}{r}\mathrm{C}_{2} \mathrm{H}_{3} \mathrm{ClF}_{2} \\
\text { (R142b) }\end{array}$ & $75-68-3$ & 1-Chloro-1,1-difluoroethane & [65] \\
\hline $\mathrm{C}_{2} \mathrm{H}_{3} \mathrm{~F}$ & $75-02-5$ & Vinyl fluoride & [65] \\
\hline $\mathrm{C}_{2} \mathrm{H}_{3} \mathrm{~F}_{3}$ (R143a) & $420-46-2$ & 1,1,1-Trifluoroethane & [65] \\
\hline $\mathrm{C}_{2} \mathrm{H}_{3} \mathrm{~N}$ & $75-05-8$ & Acetonitrile & {$[52,64]$} \\
\hline $\mathrm{C}_{2} \mathrm{H}_{4}$ & 74-85-1 & Ethylene & {$[56,59]$} \\
\hline $\mathrm{C}_{2} \mathrm{H}_{4} \mathrm{Br}_{2}$ & $106-93-4$ & Ethylene dibromide & [65] \\
\hline $\mathrm{C}_{2} \mathrm{H}_{4} \mathrm{Br}_{3}$ & $557-91-5$ & 1,1-Dibromoethane & [65] \\
\hline $\mathrm{C}_{2} \mathrm{H}_{4} \mathrm{Cl}_{2}$ & $75-34-3$ & 1,1-Dichloroethane & [65] \\
\hline $\mathrm{C}_{2} \mathrm{H}_{4} \mathrm{~F}_{2}$ (R152a) & $75-37-6$ & 1,1-Difluoroethane & [65] \\
\hline $\mathrm{C}_{2} \mathrm{H}_{4} \mathrm{O}$ & $75-21-8$ & Ethylene oxide & {$[26,62]$} \\
\hline $\mathrm{C}_{2} \mathrm{H}_{5} \mathrm{Br}$ & $74-96-4$ & Ethyl bromide & [65] \\
\hline $\mathrm{C}_{2} \mathrm{H}_{5} \mathrm{~F}$ & $353-36-6$ & Fluoroethane & [65] \\
\hline $\mathrm{C}_{2} \mathrm{H}_{6}$ & $74-84-0$ & Ethane & {$[56,59,60$} \\
\hline $\mathrm{C}_{2} \mathrm{H}_{6} \mathrm{O}$ & $115-10-6$ & Dimethyl ether & [64] \\
\hline $\mathrm{C}_{2} \mathrm{H}_{6} \mathrm{O}$ & $64-17-5$ & Ethanol & [51] \\
\hline $\mathrm{C}_{2} \mathrm{H}_{6} \mathrm{O}_{2}$ & $107-21-1$ & Ethylene glycol & [62] \\
\hline $\mathrm{C}_{2} \mathrm{H}_{6} \mathrm{~S}$ & $75-18-3$ & Dimethyl sulphide & [64] \\
\hline $\mathrm{C}_{2} \mathrm{H}_{7} \mathrm{~N}$ & $124-40-3$ & Dimethylamin & [68] \\
\hline $\mathrm{C}_{2} \mathrm{H}_{8} \mathrm{~N}_{2}$ & $57-14-7$ & 1,1-Dimethylhydrazine & [63] \\
\hline $\mathrm{C}_{2} \mathrm{HBrClF}_{3}$ & $151-67-7$ & Halothane & [65] \\
\hline $\begin{array}{c}\mathrm{C}_{2} \mathrm{HCl}_{2} \mathrm{~F}_{3} \\
(\mathrm{R} 123)\end{array}$ & $306-83-2$ & 2,2-Dichloro-1,1,1-Trifluoroethane & [65] \\
\hline $\mathrm{C}_{2} \mathrm{HCl}_{3}$ & 79-01-6 & Trichloroethylene & [65] \\
\hline $\begin{array}{l}\mathrm{C}_{2} \mathrm{HClF}_{2} \\
(\mathrm{R} 1122)\end{array}$ & $359-10-4$ & 2-Chloro-1,1-difluoroethylene & [65] \\
\hline $\mathrm{C}_{2} \mathrm{HClF}_{4}(\mathrm{R} 124)$ & $2837-89-0$ & 2-Chloro-1,1,1,2-Tetrafluoro-Ethane & [65] \\
\hline $\mathrm{C}_{2} \mathrm{HF}_{5}(\mathrm{R} 125)$ & $354-33-6$ & 1,1,1,2,2-Pentafluoroethane & [65] \\
\hline $\mathrm{C}_{2} \mathrm{~N}_{2}$ & $460-19-5$ & Cyanogen & [66] \\
\hline $\mathrm{C}_{3} \mathrm{H}_{4}$ & $463-49-0$ & Propadiene & [59] \\
\hline $\mathrm{C}_{3} \mathrm{H}_{4}$ & 74-99-7 & Propyne & [59] \\
\hline $\mathrm{C}_{3} \mathrm{H}_{6}$ & 115-07-1 & Propylene & [59] \\
\hline $\mathrm{C}_{3} \mathrm{H}_{6}$ & $75-19-4$ & Cyclopropane & [69] \\
\hline $\mathrm{C}_{3} \mathrm{H}_{6} \mathrm{O}$ & 67-64-1 & Acetone & [70] \\
\hline $\mathrm{C}_{3} \mathrm{H}_{8} \mathrm{O}$ & $67-63-0$ & Propan-2-ol & [71] \\
\hline $\mathrm{C}_{3} \mathrm{HF}_{7}$ (R227ea) & $431-89-0$ & 1,1,1,2,3,3,3-Heptafluoropropane & [72] \\
\hline $\mathrm{C}_{4} \mathrm{~F}_{10}$ & $355-25-9$ & Perfluorobutane & [73] \\
\hline $\mathrm{C}_{4} \mathrm{H}_{10}$ & $75-28-5$ & Isobutane & [64] \\
\hline $\mathrm{C}_{4} \mathrm{H}_{4} \mathrm{~S}$ & $110-02-1$ & Thiophene & [64] \\
\hline $\mathrm{C}_{4} \mathrm{H}_{8}$ & $287-23-0$ & Cyclobutane & [69] \\
\hline $\mathrm{C}_{5} \mathrm{H}_{10}$ & $287-92-3$ & Cyclopentane & [69] \\
\hline $\mathrm{C}_{6} \mathrm{H}_{4} \mathrm{Cl}_{2}$ & $95-50-1$ & Ortho-dichlorobenzene & [23] \\
\hline $\mathrm{C}_{6} \mathrm{H}_{5} \mathrm{Cl}$ & $108-90-7$ & Chlorobenzene & [23] \\
\hline $\mathrm{C}_{6} \mathrm{H}_{6}$ & $71-43-2$ & Benzene & {$[23,29]$} \\
\hline $\mathrm{C}_{6} \mathrm{H}_{6} \mathrm{O}$ & $108-95-2$ & Phenol & [74] \\
\hline $\mathrm{C}_{6} \mathrm{H}_{7} \mathrm{~N}$ & $62-53-3$ & Aniline & [74] \\
\hline $\mathrm{C}_{6} \mathrm{H}_{10} \mathrm{O}$ & $108-94-1$ & Cyclohexanone & [50] \\
\hline $\mathrm{C}_{6} \mathrm{H}_{12}$ & $110-82-7$ & Cyclohexane & {$[50,64,69$} \\
\hline $\mathrm{C}_{6} \mathrm{H}_{12} \mathrm{O}$ & $108-93-0$ & Cyclohexanol & {$[75]$} \\
\hline $\mathrm{C}_{6} \mathrm{H}_{13} \mathrm{~N}$ & $108-91-8$ & Cyclohexylamine & [74] \\
\hline $\mathrm{C}_{6} \mathrm{H}_{18} \mathrm{OSi}_{2}$ & $107-46-0$ & Hexamethyldisiloxane & [58] \\
\hline $\mathrm{C}_{7} \mathrm{H}_{8}$ & $108-88-3$ & Toluene & {$[23,29]$} \\
\hline $\mathrm{C}_{8} \mathrm{H}_{24} \mathrm{O}_{4} \mathrm{Si}_{4}$ & $556-67-2$ & Octamethylcyclotetrasiloxane & [76] \\
\hline
\end{tabular}

Each molecular force field consists of a single and unique set of parameters that is converted on demand into the desired input file format. All data are stored in the database using SQL (structured query language) to ensure flexibility and robustness with the data handling. All types of molecular force fields in the MolMod database were validated for the supported simulation programmes.

\section{Nomenclature}

A comprehensive description of the nomenclature for all supported input files is given to facilitate the integration of the 
force field input files into the workflow of a simulator. The input files for the different simulation programmes that are provided by the MolMod database contain basically only numbers in the specified formats, sometimes in combination with keywords. As such they are ready-to-use. This is sufficient for standard applications of the corresponding simulation programmes. But numbers that carry no semantics are insufficient for anything that goes beyond plug and play. Therefore, the MolMod database contains a comprehensive description of the content of the input files for all supported simulation programmes and the force field definition in the MolMod web frontend. This description of meaning of the provided data enables using the data also in non-standard applications and ensures that the contents become genuinely interoperable with data and metadata from other sources, for example for the virtual materials market place (VIMMP) where data pertaining to a variety of modelling paradigms need to be processed and made accessible to end users in a coherent way [81].

Appropriate semantic assets were defined for each entity of the database and eventually for their relations. The database was then complemented by an according nomenclature, i.e. a conceptual model of the employed entities in a descriptive form that is to be processed by humans, not by machines. This nomenclature, which is available on the MolMod web frontend, builds on - and is compatible with - the Review of Materials Modelling (RoMM) by de Baas [82]. It defines the sense in which the terms associated with the database entries are meant to be used, including, but not limited to

- geometry definitions ( $x y z$-coordinates, Z-matrix, angle and dihedral definitions, etc.)

- definition of multipole moments and equivalent point charge configurations

- employed unit systems.

\section{Summary and future work}

In the present work, the MolMod database is introduced. It is an open accessible database of molecular models for fluids and contains models of about 150 pure substances at present. The models were parametrised in previous work such as to yield a good description of experimental data of the vapour-liquid equilibrium of the studied fluid. Many of the models have also been tested with respect to caloric, transport, and interfacial properties and the predictions were often found to be in good agreement with experimental data. This makes the models provided in the MolMod database interesting for applications in chemical engineering and many other fields of science and technology.

The MolMod database provides ready-to-use input files for different common molecular simulation packages. This reduces the risk of input errors in the simulations. But the MolMod database also contains additional information: References to the original work in which the models were developed are given as well as known misprints clearly pointed out. Furthermore, the MolMod database also provides detailed descriptions of all entities in the input files that are available from the database.

The MolMod database was developed and is maintained by the Boltzmann Zuse Society of Computational Molecular
Engineering (BZS). The models that are presently included were developed and tested by BZS members, but the MolMod database is open for contributions from other groups. Any tailor-made molecular model of a fluid that fits into the scope of the MolMod database may be included, provided that its development and testing have been described in a peer-reviewed scientific paper and that a sufficiently accurate description of relevant thermophysical data is achieved. Suggestions to include new models can be filed via the MolMod homepage.

In its present version, the MolMod database only contains models of simple fluids without internal degrees of freedom. An extension to larger molecules that require the consideration of internal degrees of freedom is interesting. The same holds for an extension to the Mie potential instead of the Lennard-Jones 12-6 potential. Future work will also aim at providing input files for other molecular simulation programmes than GROMACS, LAMMPS, $m s 2$, $l s 1$ mardyn, that are already served.

Ongoing and future developments will also advance the semantic technology that underlies to the MolMod database to include (or attach to) machine-readable assets, e.g. by rigorously relating the present nomenclature, that categorises and describes atomistic and mesoscopic materials models, to the MODA Workow Graph Language [83], ontologies such as the European Materials Modelling Ontology [84], and the metadata model EngMeta [85]. This will facilitate integrating the MolMod database as a component into future development work towards open translation environments, i.e. platforms that generate materials modelling workflows that are tailored to the needs of the end user, and virtual marketplace platforms where materials modelling services and data access can be traded. Various approaches for providing such environments have so far been envisioned; $c f$. de Baas [82] for a detailed discussion of the position that semantic assets for molecular modelling and simulation, model repositories, and repositories for simulation data and metadata may occupy within a coherent approach to materials modelling interoperability and standardisation.

\section{Acknowledgments}

We gratefully appreciate running test simulations for the validation of the ls1 mardyn, GROMACS and LAMMPS input files by Matthias Heinen, Edder J. Garcia and Angelo Damone, respectively. The simulations for the parametrisation of the force fields were carried out on the HazelHen at High Performance Computing Center Stuttgart (HLRS) under the grant MMHBF2 as well as on the SuperMUC at Leibniz Supercomputing Centre (LRZ) Garching under the grant SPARLAMPE (pr48te). The present research was conducted under the auspices of the Boltzmann-Zuse Society of Computational Molecular Engineering (BZS).

\section{Disclosure statement}

No potential conflict of interest was reported by the authors.

\section{Funding}

The authors gratefully acknowledge funding of the present work by the Reinhart Koselleck programme of the Deutsche Forschungsgemeinschaft (DFG), and the TaLPas project by the German Federal Ministry of Education and Research (Bundesministerium für Bildung und Forschung) (BMBF). The co-authors Simon Stephan and Hans Hasse acknowledge funding by the European Union's “Horizon 2020 research and innovation 
programme" (grant agreement No. 694807 - ENRICO) and the co-author Martin Horsch by (grant agreement No. 760907 - VIMMP).

\section{References}

[1] Maginn EJ. From discovery to data: what must happen for molecular simulation to become a mainstream chemical engineering tool. AIChE J. 2009;55(6):1304-1310. Available from: https://onlinelibrary. wiley.com/doi/abs/10.1002/aic.11932.

[2] Economou I, Krokidas P, Michalis V. The role of molecular thermodynamics in developing industrial processes and novel products that meet the needs for a sustainable future (in the water-food-energy nexus). Boca Raton (FL): CRC Press; 2017.

[3] Vrabec J, Bernreuther M, Bungartz HJ, et al. SkaSim - skalierbare HPC-Software für molekulare Simulationen in der chemischen Industrie. Chemie Ingenieur Technik. 2018;90(3):295-306. Available from: https://onlinelibrary.wiley.com/doi/abs/10.1002/cite.201700113.

[4] Kofke DA, Siepmann JI, Chirico RD, et al. Editorial: Molecular modeling and simulation in JCED. J Chem Eng Data. 2016;61(1):1-2. Available from: https://doi.org/10.1021/acs.jced.5b01054.

[5] Schappals M, Mecklenfeld A, Kröger L, et al. Round robin study: Molecular simulation of thermodynamic properties from models with internal degrees of freedom. J Chem Theory Comput. 2017;13 (9):4270-4280. Available from: https://doi.org/10.1021/acs.jctc. $7 \mathrm{~b} 00489$.

[6] Miller BT, Singh RP, Klauda JB, et al. Charmming: A new, flexible web portal for charmm. J Chem Inf Model. 2008;48(9):1920-1929. Available from: https://doi.org/10.1021/ci800133b.

[7] Vanommeslaeghe K, Hatcher E, Acharya C, et al. CHARMM general force field: A force field for drug-like molecules compatible with the CHARMM all-atom additive biological force fields. J Comput Chem. 2010;31(4):671-690. Available from: https://onlinelibrary.wiley. com/doi/abs/10.1002/jcc.21367.

[8] Vanommeslaeghe K, MacKerell AD. Automation of the CHARMM general force field (CGenFF) I: bond perception and atom typing. J Chem Inf Model. 2012;52(12):3144-3154. https://doi.org/10.1021/ ci300363c. Available from: https://doi.org/10.1021/ci300363c..

[9] Vanommeslaeghe K, Raman EP, MacKerell AD. Automation of the CHARMM general force field (CGenFF) II: assignment of bonded parameters and partial atomic charges. J Chem Inf Model. 2012;52 (12):3155-3168. https://doi.org/10.1021/ci3003649. Available from: https://doi.org/10.1021/ci3003649..

[10] Cornell WD, Cieplak P, Bayly CI, et al. A second generation force field for the simulation of proteins, nucleic acids, and organic molecules. J Am Chem Soc. 1995;117(19):5179-5197. https://doi.org/10.1021/ ja00124a002. Available from: https://doi.org/10.1021/ja00124a002..

[11] Wang J, Wolf RM, Caldwell JW, et al. Development and testing of a general amber force field. J Comput Chem. 2004;25(9):1157-1174. Available from: https://onlinelibrary.wiley.com/doi/abs/10.1002/jcc. 20035.

[12] Wang J, Wang W, Kollman PA, et al. Automatic atom type and bond type perception in molecular mechanical calculations. J Molecular Graphics Modelling. 2006;25(2):247-260. Available from: http:// www.sciencedirect.com/science/article/pii/S1093326305001737.

[13] Scott WRP, Hünenberger PH, Tironi IG, et al. The GROMOS biomolecular simulation program package. J Phys Chem A. 1999;103 (19):3596-3607. Available from: https://doi.org/10.1021/jp984217f.

[14] Oostenbrink C, Villa A, Mark AE, et al. A biomolecular force field based on the free enthalpy of hydration and solvation: The GROMOS force-field parameter sets $53 \mathrm{a} 5$ and 53a6. J Comput Chem. 2004;25(13):1656-1676. Available from: https:// onlinelibrary.wiley.com/doi/abs/10.1002/jcc.20090.

[15] Jorgensen WL, Tirado-Rives J. Potential energy functions for atomic-level simulations of water and organic and biomolecular systems. Proc National Academy Sci. 2005;102(19):6665-6670. Available from: http://www.pnas.org/content/102/19/6665.

[16] Jorgensen WL, Maxwell DS, Tirado-Rives J. Development and testing of the OPLS all-atom force field on conformational energetics and properties of organic liquids. J Am Chem Soc. 1996;118
(45):11225-11236. Available from: https://doi.org/10.1021/ ja9621760.

[17] Dodda LS, Cabeza de Vaca I, Tirado-Rives J, et al. LigParGen web server: an automatic OPLS-AA parameter generator for organic ligands. Nucleic Acids Res. 2017;45(W1):W331-W336. Available from: https://dx.doi.org/10.1093/nar/gkx312.

[18] Eggimann BL, Sunnarborg AJ, Stern HD, et al. An online parameter and property database for the TraPPE force field. Mol Simul. 2014;40 (1-3):101-105. Available from: https://doi.org/10.1080/08927022. 2013.842994.

[19] Ungerer P, Beauvais C, Delhommelle J, et al. Optimization of the anisotropic united atoms intermolecular potential for n-alkanes. J Chem Phys. 2000;112(12):5499-5510. Available from: https://doi. org/10.1063/1.481116.

[20] Bourasseau E, Haboudou M, Boutin A, et al. New optimization method for intermolecular potentials: optimization of a new anisotropic united atoms potential for olefins: prediction of equilibrium properties. J Chem Phys. 2003;118(7):3020-3034. Available from: https://doi.org/10.1063/1.1537245.

[21] Delhommelle J, Tschirwitz C, Ungerer P, et al. Derivation of an optimized potential model for phase equilibria (OPPE) for sulfides and thiols. J Phys Chem B. 2000;104(19):4745-4753. Available from: https://doi.org/10.1021/jp994064b.

[22] TU Kaiserslautern/ TU Berlin. Molmod database of the Boltzmann Zuse Society for Computational Engineering [internet]; 2018. Available from: http://molmod.boltzmann-zuse.de

[23] Huang YL, Heilig M, Hasse $\mathrm{H}$, et al. Vapor-liquid equilibria of hydrogen chloride, phosgene, benzene, chlorobenzene, orthodichlorobenzene, and toluene by molecular simulation. AIChE J. 2011;57(4):1043-1060.

[24] Merker T, Engin C, Vrabec J, et al. Molecular model for carbon dioxide optimized to vapor-liquid equilibria. J Chem Phys. 2010;132 (23):234512.

[25] Schnabel T, Srivastava A, Vrabec J, et al. Hydrogen bonding of methanol in supercritical $\mathrm{CO}_{2}$ : comparison between $1 \mathrm{~h}$ NMR spectroscopic data and molecular simulation results. J Phys Chem B. 2007;111(33):9871-9878.

[26] Eckl B, Vrabec J, Hasse H. On the application of force fields for predicting a wide variety of properties: Ethylene oxide as an example. Fluid Phase Equilib. 2008;274(1-2):16-26.

[27] Schnabel T, Vrabec J, Hasse H. Unlike lennard-jones parameters for vapor-liquid equilibria. J Mol Liq. 2007;135(1-3):170-178.

[28] Eckl B, Vrabec J, Hasse H. An optimised molecular model for ammonia. Mol Phys. 2008;106(8):1039-1046.

[29] Guevara-Carrion G, Janzen T, Muñoz-Muñoz YM, et al. Mutual diffusion of binary liquid mixtures containing methanol, ethanol, acetone, benzene, cyclohexane, toluene, and carbon tetrachloride. J Chem Phys. 2016;144(12):124501.

[30] Thol M, Rutkai G, Köster A, et al. Fundamental equation of state for ethylene oxide based on a hybrid dataset. Chem Eng Sci. 2015 jan;121:87-99.

[31] Werth S, Horsch M, Hasse H. Molecular simulation of the surface tension of 33 multi-site models for real fluids. J Mol Liq. 2017;235:126-134. Physics of Liquid Matter: Modern Problems. PLMMP-2016 Conference; Available from: http://www. sciencedirect.com/science/article/pii/S0167732216329658.

[32] Becker S, Werth S, Horsch M, et al. Interfacial tension and adsorption in the binary system ethanol and carbon dioxide: Experiments, molecular simulation and density gradient theory. Fluid Phase Equilib. 2016;427:476.

[33] Stephan S, Langenbach K, Hasse H. Enrichment of components at vapour - liquid interfaces: a study by molecular simulation and density gradient theory. Chem Eng Transact. 2018;69:295-300. Available from: https://www.cetjournal.it/index.php/cet/article/ view/CET1869050.

[34] Vrabec J, Huang Yl, Hasse H. Molecular models for 267 binary mixtures validated by vapor-liquid equilibria: a systematic approach. Fluid Phase Equilib. 2009;279(2):120-135.

[35] Plimpton S. Fast parallel algorithms for short-range molecular dynamics. J Comput Phys. 1995;117:1-19. 
[36] van der Spoel D, Lindahl E, Hess B, et al. GROMACS: Fast, flexible, and free. J Comput Chem. 2005;26(16):1701-1718. Available from: https://onlinelibrary.wiley.com/doi/abs/10.1002/jcc.20291.

[37] Rutkai G, Köster A, Guevara-Carrion G, et al. ms2: A molecular simulation tool for thermodynamic properties, release 3.0. Comput Phys Commun. 2017;221:343-351. Available from: http://www. sciencedirect.com/science/article/pii/S0010465517302527.

[38] Niethammer C, Becker S, Bernreuther M, et al. ls1 mardyn: the massively parallel molecular dynamics code for large systems. J Chem Theory Comput. 2014;10(10):4455.

[39] van der Spoel D, van Maaren PJ, Caleman C. GROMACS molecule and liquid database. Bioinformatics. 2012;28(5):752-753. Available from: http://dx.doi.org/10.1093/bioinformatics/bts020.

[40] Hermjakob H, Montecchi-Palazzi L, Lewington C, et al. IntAct: an open source molecular interaction database. Nucleic Acids Res. 2004;32:452-455. Available from: http://dx.doi.org/10.1093/nar/ gkh052.

[41] Zanzoni A, Montecchi-Palazzi L, Quondam M, et al. MINT: a molecular interaction database. FEBS Lett. 2002;513(1):135-140. Available from: http://www.sciencedirect.com/science/article/pii/ S0014579301032938.

[42] Irwin JJ, Shoichet BK. ZINC - a free database of commercially available compounds for virtual screening. J Chem Inf Model. 2005;45 (1):177-182. Available from: https://doi.org/10.1021/ci049714+.

[43] Lorentz HA. Ueber die Anwendung des Satzes vom Virial in der kinetischen Theorie der Gase. Ann Phys. 1881;12:127-136.

[44] Berthelot D. Sur le mélange des gaz. Comptes rendus hebdomadaires des séances de l'Académie des Sciences. 1898;126:1703-1706.

[45] Deublein S, Eckl B, Stoll J, et al. ms2: a molecular simulation tool for thermodynamic properties. Comput Phys Commun. 2011;182 (11):2350-2367. Available from: http://www.sciencedirect.com/ science/article/pii/S0010465511002025.

[46] Stone AJ. Intermolecular potentials. Science. 2008;321(5890):787-789.

[47] Garzon B, Lago S, Vega C, et al. Computer simulation of vaporliquid equilibria of linear quadrupolar fluids departures from the principle of corresponding states. J Chem Phys. 1994;101(5):41664176. Available from: https://doi.org/10.1063/1.467467.

[48] Gray C, Gubbins K. Theory of molecular fluids. New York: Oxford University Press; 1984.

[49] Stoll J, Vrabec J, Hasse H, et al. Comprehensive study of the vapourliquid equilibria of the pure two-centre Lennard-Jones plus pointquadrupole fluid. Fluid Phase Equilib. 2001;179(1-2):339-362.

[50] Merker T, Vrabec J, Hasse H. Molecular simulation study on the solubility of carbon dioxide in mixtures of cyclohexane+ cyclohexanone. Fluid Phase Equilib. 2012;315:77-83.

[51] Schnabel T, Vrabec J, Hasse H. Henry's law constants of methane, nitrogen, oxygen and carbon dioxide in ethanol from 273 to $498 \mathrm{~K}$ : prediction from molecular simulation. Fluid Phase Equilib. 2005;233(2):134-143.

[52] Deublein S, Metzler P, Vrabec J, et al. Automated development of force fields for the calculation of thermodynamic properties: acetonitrile as a case study. Mol Simul. 2013;39(2):109-118.

[53] Merker T, Vrabec J, Hasse H. Engineering molecular models: efficient parameterization procedure and cyclohexanol as case study. Soft Mater. 2012;10(1-3):3-25. Available from: https://doi. org/10.1080/1539445X.2011.599695.

[54] Krämer A, Hülsmann M, Köddermann T, et al. Automated parameterization of intermolecular pair potentials using global optimization techniques. Comput Phys Commun. 2014;185(12):3228-3239. Available from: http://www.sciencedirect.com/science/article/pii/ S0010465514003038.

[55] Stöbener K, Klein P, Reiser S, et al. Multicriteria optimization of molecular force fields by Pareto approach. Fluid Phase Equilib. 2014;373:100-108. Available from: http://www.sciencedirect.com/ science/article/pii/S0378381214002210.

[56] Stöbener K, Klein P, Horsch M, et al. Parametrization of two-center Lennard-Jones plus point-quadrupole force field models by multicriteria optimization. Fluid Phase Equilib. 2016;411:33-42. Available from: http://www.sciencedirect.com/science/article/pii/S037838121 5302338 .
[57] Kohns M, Werth S, Horsch M, et al. Molecular simulation study of the $\mathrm{CO}_{2}-\mathrm{N}_{2} \mathrm{O}$ analogy. Fluid Phase Equilib. 2017;442:44-52.

[58] Thol M, Dubberke F, Rutkai G, et al. Fundamental equation of state correlation for hexamethyldisiloxane based on experimental and molecular simulation data. Fluid Phase Equilib. 2016;418:133-151. Available from: http://www.sciencedirect.com/science/article/pii/ S0378381215301527.

[59] Vrabec J, Stoll J, Hasse H. A set of molecular models for symmetric quadrupolar fluids. J Phys Chem B. 2001;105(48):12126-12133.

[60] Vrabec J, Kedia GK, Fuchs G, et al. Comprehensive study of the vapour-liquid coexistence of the truncated and shifted LennardJones fluid including planar and spherical interface properties. Mol Phys. 2006;104(9):1509-1527.

[61] Köster A, Thol M, Vrabec J. Molecular models for the hydrogen age: hydrogen, nitrogen, oxygen, argon, and water. J Chem Eng Data. 2018;63(2):305-320. Available from: https://doi.org/10.1021/acs. jced.7b00706.

[62] Huang YL, Merker T, Heilig M, et al. Molecular modeling and simulation of vapor-liquid equilibria of ethylene oxide, ethylene glycol, and water as well as their binary mixtures. Ind Eng Chem Res. 2012;51(21):7428-7440.

[63] Elts E, Windmann T, Staak D, et al. Fluid phase behavior from molecular simulation: hydrazine, monomethylhydrazine, dimethylhydrazine and binary mixtures containing these compounds. Fluid Phase Equilib. 2012;322-323:79-91.

[64] Eckl B, Vrabec J, Hasse H. Set of molecular models based on quantum mechanical ab initio calculations and thermodynamic data. J Phys Chem B. 2008;112(40):12710-12721.

[65] Stoll J, Vrabec J, Hasse H. A set of molecular models for carbon monoxide and halogenated hydrocarbons. J Chem Phys. 2003;119 (21):11396-11407.

[66] Miroshnichenko S, Grützner T, Staak D, et al. Molecular simulation of the vapor-liquid phase behavior of cyanides and their binary mixtures. Fluid Phase Equilib. 2013;354:286-297.

[67] Schnabel T, Cortada M, Vrabec J, et al. Molecular model for formic acid adjusted to vapor-liquid equilibria. Chem Phys Lett. 2007;435 (4):268-272.

[68] Schnabel T, Vrabec J, Hasse H. Molecular simulation study of hydrogen bonding mixtures and new molecular models for mono- and dimethylamine. Fluid Phase Equilib. 2008;263(2):144-159.

[69] Muñoz-Muñoz YM, Guevara-Carrion G, Llano-Restrepo M, et al. Lennard-Jones force field parameters for cyclic alkanes from cyclopropane to cyclohexane. Fluid Phase Equilib. 2015;404:150-160.

[70] Windmann T, Linnemann M, Vrabec J. Fluid phase behavior of nitrogen + acetone and oxygen + acetone by molecular simulation, experiment and the peng-robinson equation of state. J Chem Eng Data. 2014;59(1):28-38.

[71] Munoz-Munoz YM, Guevara-Carrion G, Vrabec J. Molecular insight into the liquid propan-2-ol + water mixture. J Phys Chem B. 2018;122(37):8718-8729. Available from: https://doi.org/10.1021/ acs.jpcb.8b05610.

[72] Eckl B, Huang YL, Vrabec J, et al. Vapor pressure of R227ea + ethanol at $343.13 \mathrm{~K}$ by molecular simulation. Fluid Phase Equilib. 2007;260(2):177-182.

[73] Koester A, Nandi P, Windmann T, et al. Vapor-liquid equilibria of ethylene $\left(\mathrm{C}_{2} \mathrm{H}_{4}\right)+$ decafluorobutane $\left(\mathrm{C}_{4} \mathrm{~F}_{1} 0\right)$ at $268-298 \mathrm{~K}$ from experiment, molecular simulation and the Peng-Robinson equation of state. Fluid Phase Equilib. 2012;336:104-112.

[74] Munoz-Munoz YM, Hsieh CM, Vrabec J. Understanding the differing fluid phase behavior of cyclohexane + benzene and their hydroxylated or aminated forms. J Phys Chem B. 2017;121 (21):5374-5384. Available from: https://doi.org/10.1021/acs.jpcb. $7 \mathrm{~b} 02494$.

[75] Merker T, Guevara-Carrion G, Vrabec J, et al. Molecular modeling of hydrogen bonding fluids: new cyclohexanol model and transport properties of short monohydric alcohols. In: Nagel WE, Kröner DB, Resch MM editors. High performance computing in science and engineering 08. Berlin, Heidelberg: Springer; 2009. p. 1. Available from: https://doi.org/10.1007/978-3-54088303-6\37 
[76] Thol M, Rutkai G, Köster A, et al. Thermodynamic properties of octamethylcyclotetrasiloxane. J Chem Eng Data. 2016;61(7):25802595. Available from: https://doi.org/10.1021/acs.jced.6b00261.

[77] Reiser S, Deublein S, Vrabec J, et al. Molecular dispersion energy parameters for alkali and halide ions in aqueous solution. J Chem Phys. 2014;140(4):044504.

[78] Deublein S, Reiser S, Vrabec J, et al. A set of molecular models for alkaline-earth cations in aqueous solution. J Phys Chem B. 2012;116(18):5448-5457.

[79] Deublein S, Vrabec J, Hasse H. A set of molecular models for alkali and halide ions in aqueous solution. J Chem Phys. 2012;136 (8):044504.

[80] Engin C, Vrabec J, Hasse H. On the difference between a point multipole and an equivalent linear arrangement of point charges in force field models for vapour-liquid equilibria; partial charge based models for 59 real fluids. Mol Phys. 2011;109(16):1975-1982.

[81] Virtual materials marketplace (VIMMP); 2019. Available from: https://vimmp.eu

[82] de Baas AF, editor. What makes a material function? let me compute the ways... Luxembourg: EU Publications Office; 2017. This source is commonly referred to as the Review of Materials Modelling (RoMM)

[83] Schmitz GJ, Carravetta V, Luisier M, et al. Materials modelling: terminology, classification and metadata, cen workshop agreement 17284. Brussels: CEN-CENELEC Management Centre; 2018.

[84] Ghedini E, Goldbeck G. European materials modelling ontology (to appear). 2019.

[85] Schembera B, Iglezakis D. The genesis of EngMeta: a metadata model for research data in computational engineering (to appear). 2019. 